\title{
Treating Diabetic Peripheral Neuropathy Using a Novel, Nanotechnology-Based Topical Formulation to Improve Pain, Sensitivity, and Function
}

\author{
Jeffery LaMour, DPM', Douglas Grimm, DPM², Ester Smith, PhD ${ }^{3}$, Zvi Yaniv, PhD" and Peter Hurwitz ${ }^{5^{*}}$
}

\author{
${ }^{1}$ Jeffery LaMour, DPM, PA, Austin, Texas, USA \\ ${ }^{2}$ Foot Associates of Central Texas, LLC, Austin, Texas, USA \\ ${ }^{3} E G S$ Research \& Consulting, Austin, Texas, USA \\ ${ }^{4}$ PeriphEX Corp, Austin, Texas, USA \\ ${ }^{5}$ Clarity Science LLC, Narragansett, Rhode Island, USA
}

*Corresponding author: Peter Hurwitz, Clarity Science LLC, 750 Boston Neck Road, Suite 11, Narragansett, RI 02882, USA, Tel: +1917-757-0521, Fax: +1855-891-8303

\begin{abstract}
Diabetes has become one of the largest global healthcare problems of the $21^{\text {st }}$ century. More than 100 million U.S. adults are now living with diabetes or pre-diabetes. The Centers for Disease Control and Prevention (CDC) reports that as of $2015,30.3$ million Americans $(9.4 \%$ of the U.S. population) have diabetes and 1.5 million Americans are diagnosed with diabetes every year. The population prevalence of diabetes in the US is approaching $10 \%$ and is increasing by $5 \%$ each year.
\end{abstract}

Annual costs for diabetic management are over $\$ 300$ billion (USD). It has been estimated that about $27 \%$ of health-care costs of diabetes can be attributed to Diabetic Peripheral Neuropathy (DPN). DPN is the most common complication associated with diabetes mellitus and causes a broad spectrum of neuropathic complications, including acute and chronic forms, affecting each level of the peripheral nerves. DPN has a lifetime prevalence of approximately $50 \%$ and is the most common diabetic complication. DPN is a leading cause for disability due to foot ulceration and amputation, gait disturbance, and fall-related injury. Approximately $20 \%$ to $30 \%$ of patients with DPN suffer from neuropathic pain. DPN significantly lowers quality of life and substantially increases health costs associated with diabetes.

There are several treatment options currently available, including vitamins, physical therapy, or topical interventions which have shown limited efficacy. The most common drugs
(Gabapentin, Pregabalin) used to treat neuropathic symptoms have limited effectiveness and are frequently associated with substantial side effects. Overall, most patients are dissatisfied with their treatment and many of them are actively looking for better solutions. Ongoing research is needed to identify efficacious, safe, and minimally invasive therapies that provide optimal benefit and minimal harm, with the goal of reducing pain severity, improving function, and improving quality of life.

Technological advancements have allowed for the incorporation of nanotechnology into the development of new innovative therapies; yet, there remains a paucity of data surrounding them. The paper summarizes the results of an approved Institutional Review Board (IRB) - minimal risk, observational study-in order to evaluate the utilization of gas nanobubbles for treating foot Diabetic Peripheral Neuropathy (DPN) Symptoms. The study used patient perceptions and physician reported clinical assessments, to evaluate the efficacy and safety of novel nanotechnologyformulated, topically-applied hydrogel emulsion, screen for unanticipated adverse effects and proof of concept. The hydrogel emulsion consists of distilled water containing UltraFine Nanobubbles (UFNBs) of $\mathrm{O}_{2}$ and $\mathrm{CO}_{2}$ for the symptomatic treatment of DPN. Outcomes show that a considerable percent of patients experienced $50 \%$ or more improvement in their pain level across the different types of pain (tingling, numbness and burning pain) and the improvements are statistically significant.

Citation: LaMour J, Grimm D, Smith E, Yaniv Z, Hurwitz P (2021) Treating Diabetic Peripheral Neuropathy Using a Novel, Nanotechnology-Based Topical Formulation to Improve Pain, Sensitivity, and Function. Int J Diabetes Clin Res 8:149. doi.org/10.23937/2377-3634/1410149

Accepted: September 22, 2021: Published: September 24, 2021

Copyright: (c) 2021 LaMour J, et al. This is an open-access article distributed under the terms of the Creative Commons Attribution License, which permits unrestricted use, distribution, and reproduction in any medium, provided the original author and source are credited. 


\section{Keywords}

Nanotechnology, Hydrogel, Diabetic peripheral neuropathy (DPN), NoxyPure, Ultrafine nanobubbles (UFNBs), Gas nanobubbles

\section{Introduction}

Despite the global prevalence and severe complications of diabetes mellitus, the pathophysiological mechanisms of diabetic neuropathies have not been elucidated. Ongoing research does not yet fully understand why some patients develop painful neuropathy while others do not. Nonetheless it is well known that diabetic neuropathy is unpredictable, and it has a significant bearing on the lives of diabetic patients.

Beyond strict control of glucose levels, therapy that can unequivocally arrest or reverse progressive neuropathy is still elusive, along with treatments that may not have serious side effects [1-3].

It has been postulated that hypoxia may be the cause of diabetic polyneuropathy due to nerve ischemia; it is thought that nerve ischemia is due to an increase in the wall thickness of the basal lamina of vessels that perfuse peripheral nerves. Nerve biopsies show thickening of the basement membrane of the capillaries that provide nutrients. In addition, there is a reduction in diameter of the lumen. Early in the disease there may be a physiological shunt that occurs creating a hypoxic state in the absence of demonstrable signs of ischemia [4].

Prevention of diabetic neuropathies focuses on glucose control and lifestyle modifications [5]. However, no compelling evidence exists in support of glycemic control or lifestyle management as therapies for neuropathic pain in diabetes or prediabetes $[6,7]$, which leaves limited options for treatment.

Current guidelines from the American Diabetes Association on managing DPN encourage a multi-modal approach to managing pain that includes topical, noninvasive, and non-pharmacological approaches $[5,8]$.

At present, despite serious side effects, pharmaceutical interventions include gabapentinoids (Pregabalin and Gabapentin) that are calcium channel $\alpha 2-\delta$ subunit ligands, and Duloxetine, a selective norepinephrine and serotonin reuptake inhibitor (SSRI). Both have received regulatory approval for the treatment of neuropathic pain in diabetes by the U.S. Food and Drug Administration (FDA), Health Canada, and the European Medicines Agency. Gabapentin and Pregabalin have shown efficacy in a number of clinical trials for treating the pain associated with distal symmetric polyneuropathy (DSPN) [9-16]. However, not all painful DSPN studies, some of which are unpublished, have been positive $[17,18]$.

Other non-pharmaceutical approaches such as vitamins or physical therapy have shown to have very limited efficacy. It has been reported that atmospheric oxygen, in-vivo, penetrates the dermis below the skin surface [19]. Recent studies demonstrate that healing of hypoxic tissue relies more on the oxygen direct diffusion rather than delivery of oxygen by systematic circulation. Of late, Hyperbaric Oxygen Therapy (HBOT) was introduced whereby $100 \%$ oxygen gas is delivered over the entire body in a special chamber at two or three times atmospheric pressure. This process creates a pressure gradient that allows oxygen gas to diffuse into hypoxic tissues. HBOT has been shown to be an effective treatment for neuropathy. By driving oxygen deep into tissues, it reduces cell death and pain symptoms. Hyperbaric oxygen also stimulates the growth of new blood vessels, enabling the body to increase effective oxygen and nutrient delivery. A number of new studies show that this method may improve wound healing [17]. However, HBOT may have severe side effects such as lung damage, sinus damage, changes in hearing and vision, and even oxygen poisoning [20].

In an offshoot of HBOT, researchers utilized topical oxygen therapy methods using local pressurized oxygen in a special enclosure which encircle the affected area [21]. This method is cumbersome, involves long-term treatment, and is not convenient for homecare use.

\section{Gas Nanobubbles}

Over the past several years, there have been significant advancements in the nanotechnology field as it relates to developing next generation drug delivery systems. These advancements have led to the incorporation of nanoparticles for targeted treatments. Nanoparticles (with a radius $\leq 100 \mathrm{~nm}$ ) have shown promise in chemotherapy, organ targeting, and the delivery of bioactive agents [22]. Due to their unique properties, nanoparticles have been identified as having great promise in many multidisciplinary domains [18,2337]. Nanoparticles possess unique electrical, chemical, mechanical and magnetic properties that allow the development of several new classes of materials that may present advantages over traditional materials $[38,39]$. For perspective, a nanometer is one billionth of a meter and several orders of magnitude smaller than a micron, approximately the size of a molecule itself. The advances in understanding of the interaction between nanoparticles with cells and tissues, at a molecular level, allow the achievement of a high degree of functional specificity [40].

A relative new class of nanoparticles are gas nanobubbles with a mean radius of less than $100 \mathrm{~nm}$. One of the unique aspects of gas nanobubbles in aqueous solution is their negative surface charge at the interface of the gas in the nanobubble with the surrounding water. As a result, they are very stable in water solutions with concentrations as large as $10^{9}$ nanobubbles per milliliter. Ultrafine nanobubbles (UFNB) of oxygen have been shown to reduce cellular hypoxia and to possess 
anti-inflammatory and neuro-protective properties [21]. Furthermore, normal saline solution containing oxygen nanobubbles is effective for improving blood oxygenation [41]. Thus, the use of oxygen UFNBs in a water-based solution is a potentially effective, novel method for improving blood oxygenation in cases involving hypoxia, ischemic diseases, infection control, and anticancer chemoradiation therapies [42].

$\mathrm{O}_{2}$ and $\mathrm{CO}_{2}$ gasses in aqueous solutions applied topically in the form of UFNBs are designed to drive both gasses deep into tissues [19]. $\mathrm{O}_{2}$ and $\mathrm{CO}_{2}$ nanobubbles are directly absorbed by the skin and then supplied exclusively to the outer layers of the skin. It is important to note that $\mathrm{CO}_{2}$ delivery to the skin results in vasodilation having beneficial effects for local increased blood flow and added oxygenation due to the "Bohr effect" [43].

As the physiopathology of Diabetic Peripheral Neuropathy seems to involve hypoxia of the peripheral nerves, the hypothesis of this study was that immersing the feet of patients suffering from DPN symptoms into a water solution containing a high concentration of $\mathrm{O}_{2}$ and $\mathrm{CO}_{2}$ UFNBs may alleviate these symptoms at least for a period of time. It is expected that the proposed treatment could represent a safer, simpler, less expensive home-care alternative to HBOT for diabetic patients suffering from peripheral neuropathy.

Recently, small microbubbles were used for several medical applications such as contrast agents for ultrasound diagnosis as well as for drug and gene delivery [44], but the concept of the utilization of UFNBs as topical agents for tissue oxygenation is sparsely mentioned in the literature [45]. Understanding the unique properties of $\mathrm{O}_{2}$ and $\mathrm{CO}_{2}$ UFNBs led to the development of a new type of emulsion of oxygen nanobubbles in water absorbed in a hydrogel for TOT, Topical Oxygen Therapy (NoxyPure, PeriphEX Corp., Austin, Texas USA). An IRB approved observational study was conceived to evaluate patient perceptions and clinician reported assessments of the safety and efficacy of NoxyPure for the treatment of Diabetic Peripheral Neuropathy Symptoms.

\section{Methods}

\section{Materials and treatment}

The materials and treatment utilized in our research included distilled water (1 ppm), medical oxygen and carbon dioxide with a purity of $99.9 \%$, Sodium Polyacrylate powder and a proprietary ceramic nanobubbler [46].

The proprietary method achieved gas nanobubbled water with desired characteristics of a mean radius of $100 \mathrm{~nm}$ and concentration of $10^{8}-10^{9}$ nanobubbles per milliliter.

A dose of $450 \mathrm{ml}$ of a novel hydrogel emulsion was topically applied to each foot for a least 20 minutes. The emulsion consisted of distilled water containing UFNBs of $\mathrm{CO}_{2}$ and $\mathrm{O}_{2}$ (NoxyPure, PeriphEX Corporation, Austin, TX USA). Each dose consisted of $3 \mathrm{~g}$ of Sodium Polyacrylate powder which absorbs the gas nanobubbled distilled water forming a hydrogel.

\section{Study design}

This study is a prospective, Institutional Review Boardapproved Observational Study aimed at evaluating physician reported clinical assessments of the efficacy and safety of UltraFine Nanobubbles (UFNBs) of $\mathrm{O}_{2}$ and $\mathrm{CO}_{2}$ for the symptomatic topical treatment of Diabetic Peripheral Neuropathy and patient perceptions.

The only laboratory assessment requirement to meet the enrollment inclusion criteria was a glycated hemoglobin - HbA1c - no greater than $11 \%$.

Patients filled out a Visual Analog Scale and a pain management questionnaire at enrollment and at each subsequent visit and treatment. A complete clinical evaluation to provide objective assessment of the neuropathic symptoms was performed at the time of enrollment, after treatment \#7 of 10, and within 1-week and 1-month after the last treatment. The clinical evaluation includes a Toronto Neuropathy Score as well as a Semmes-Weinstein 5.07 (10 g) Monofilament Examination.

Descriptive statistics were calculated and used $\mathrm{G}^{*}$ power [47] to estimate the required sample size to detect an effect. We assumed a paired samples T-test design, estimating average pain reduction from baseline to one week and one month after completion of the treatments.

The study of the IRB approved protocol was performed in full accordance with the rules of the Health Insurance Portability and Accountability Act of 1996 (HIPAA) and the principles of the declaration of Helsinki and the international council of Harmonisation/ GCP. All patients gave informed and written consent.

\section{Subjects}

Subjects for the study were chosen from patients with persistent but controlled diabetes and no open lower-extremity ulcers, with diagnosed DPN and not on high doses of opioid pain relievers. Patient inclusion and exclusion criteria for the study were as follows:

Patients were recruited from four investigator clinics in Austin, TX, USA. After the physician decided to prescribe UltraFine Nanobubbles (UFNBs) as part of the treatment plan, all patients that met the inclusion criteria were offered the option to participate in the study, and if accepted and after consenting, received the treatment free of charge. De-identified subject survey responses and clinical assessment findings were provided to PeriphEX Corp. 
All diagnostic tests and treatment decisions were made at the discretion of clinicians.

The paper focuses on 21 subjects who each received ten treatments (Table 1 ).

\section{Study procedures and assessments}

The study was designed as a longitudinal, selfcontrolled trial that included one treatment group using a hydrogel emulsion of UltraFine Nanobubbles (UFNBs) of $\mathrm{O}_{2}$ and $\mathrm{CO}_{2}$ prepared by PeriphEX Corp, Austin, Texas. The treatment consisted of ten treatments administered over a period not longer than six weeks. The ten treatments were administered through physician visual and in-person testing and observation, in addition to subject surveys. The Treatment Protocol and the Pain Questionnaire were completed for each treatment, one week and one month after final treatment. The Toronto Neuropathy Score and the Semmes-Weinstein test were completed by physicians to measure the level of the patient's neuropathy in the right foot and left foot.

\section{Outcome measurements}

There were two primary endpoints:
- Statistically significant relief of pain symptomatology as assessed by a Visual Analog Scale.

- Statistically significant improvement of objective foot sensitivity as evaluated by the SemmesWeinstein test and Toronto Neuropathy score.

There were three secondary endpoints:

- Measuring the change in narcotics, painkillers and other medicines that patients are taking to alleviate the neuropathic symptoms during the trial period.

- Measuring the effects of the treatment on the global evolution of the Neuropathy over a period of one month after the last treatment, using the Total Neuropathy Score (TNS) and its subscales of the Mayo Clinic measures of neuropathy and neuropathy symptom score (NSS).

- Reporting on local complications and any observed or reported adverse events.

\section{Results}

\section{Key highlights}

The percentage of subjects experiencing pain

Table 1: Subject demographics.

\begin{tabular}{|l|l|l|}
\hline Age $(\mathrm{n}=21)$ & $82-83(\mathrm{n}=2)$ & $9.5 \%$ \\
& $71-79(\mathrm{n}=8)$ & $38.1 \%$ \\
& $63-71(\mathrm{n}=10)$ & $47.6 \%$ \\
& No age data $(\mathrm{n}=1)$ & $4.8 \%$ \\
\hline Gender & Male $(\mathrm{n}=13)$ & $61.9 \%$ \\
& Female $(\mathrm{n}=8)$ & $38.1 \%$ \\
\hline Ethnicity & Caucasian $(\mathrm{n}=14)$ & $66.6 \%$ \\
& African American $(\mathrm{n}=3)$ & $14.3 \%$ \\
& Hispanic $(\mathrm{n}=3)$ & $14.3 \%$ \\
\hline & Asian American $(\mathrm{n}=1)$ & $4.8 \%$ \\
\hline
\end{tabular}

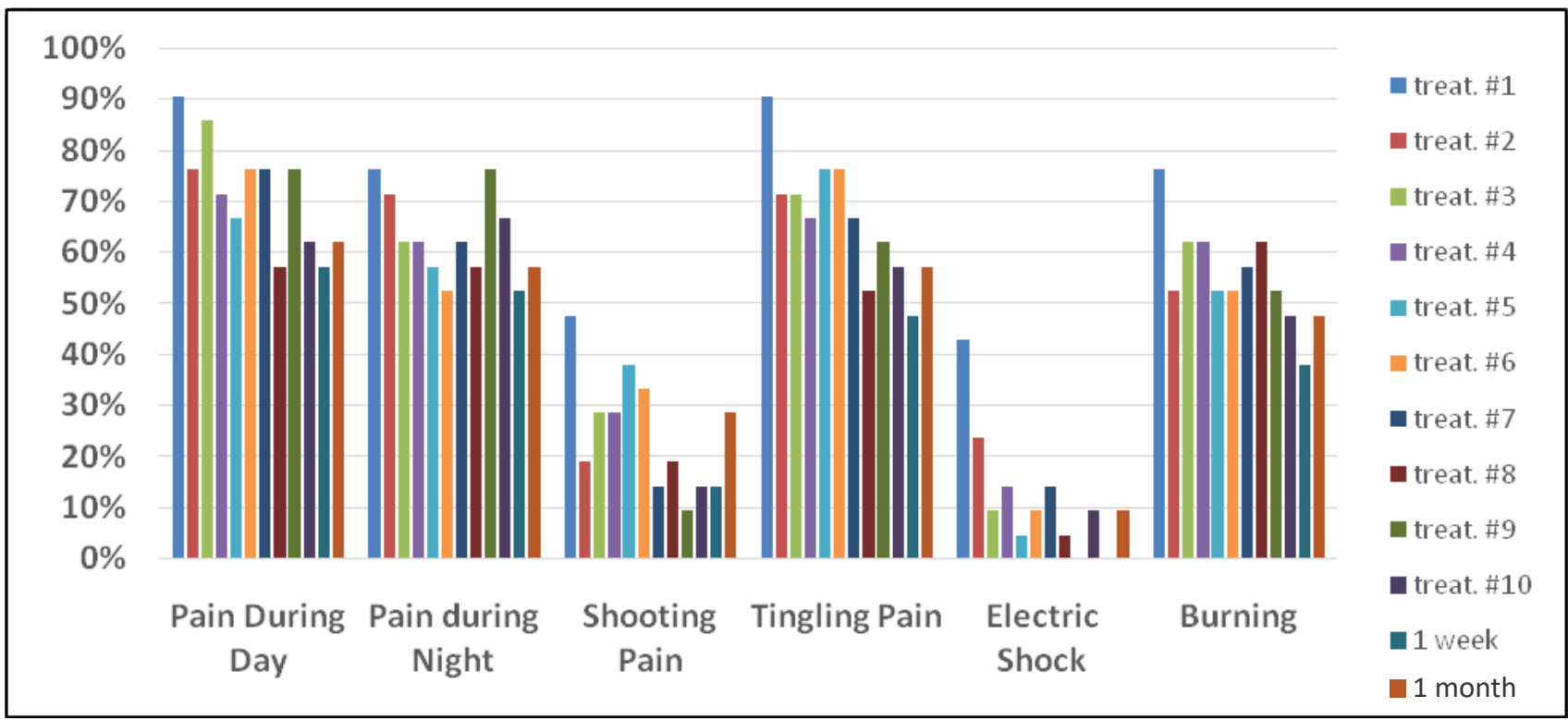

Figure 1: A graphical representation of the percentage of subjects experiencing pain. 
during the day or night and the percentage of subjects experiencing different types of pain decreased with the treatments (Figure 1).

Subjects experienced improvement (decrease) in all types and levels (Usual and Maximum) of pain after the final treatment, one week and one month after the final treatment (Table 2).
Changes in usual and maximum tingling, numbness, and burning over time decreased, implying that the usual and maximum level of tingling, numbness and burning diminished as the number of treatments increased, and that the decrease is statistically significant (Table 2 and Table 3).

A substantial fraction of subjects experienced 50

Table 2: Usual and Maximum Pain by Type of Pain, Benchmarks and \% of Improvement.

\begin{tabular}{|c|c|c|c|c|c|c|c|c|}
\hline $\begin{array}{l}\text { Type and } \\
\text { extent of pain }\end{array}$ & T \#1 & T \#7 & T \#10 & $\begin{array}{l}\text { One Week } \\
\text { After T \#10 }\end{array}$ & $\begin{array}{l}\text { One Month } \\
\text { After T \#10 }\end{array}$ & $\begin{array}{l}\text { Relative } \\
\text { Improvement } \\
\text { After T \#10 }\end{array}$ & $\begin{array}{l}\text { Relative } \\
\text { Improvement } \\
\text { 1-week After } \\
\text { T\#10 }\end{array}$ & $\begin{array}{l}\text { Relative } \\
\text { Improvement } \\
\text { 1-month After } \\
\text { T \#10 }\end{array}$ \\
\hline $\begin{array}{l}\text { Tingling Pain - } \\
\text { Usual }\end{array}$ & $\begin{array}{l}4.57 \\
\pm 0.52\end{array}$ & $\begin{array}{l}2.14 \\
\pm 0.59\end{array}$ & $\begin{array}{l}2.14 \\
\pm 0.63\end{array}$ & $\begin{array}{l}1.90 \\
\pm 0.60\end{array}$ & $\begin{array}{l}2.52 \\
\pm 0.57\end{array}$ & $53.2 \%$ & $58.4 \%$ & $44.9 \%$ \\
\hline $\begin{array}{l}\text { Tingling Pain - } \\
\text { Max }\end{array}$ & $\begin{array}{l}6.48 \\
\pm 0.60\end{array}$ & $\begin{array}{l}3.86 \\
\pm 0.72\end{array}$ & $\begin{array}{l}3.14 \\
\pm 0.74\end{array}$ & $\begin{array}{l}2.81 \\
\pm 0.73\end{array}$ & $\begin{array}{l}4.05 \\
\pm 0.71\end{array}$ & $51.5 \%$ & $56.6 \%$ & $37.5 \%$ \\
\hline $\begin{array}{l}\text { Numbness - } \\
\text { Usual }\end{array}$ & $\begin{array}{l}5.48 \\
\pm 0.61\end{array}$ & $\begin{array}{l}4.38 \\
\pm 0.57\end{array}$ & $\begin{array}{l}3.95 \\
\pm 0.55\end{array}$ & $\begin{array}{l}3.90 \\
\pm 0.60\end{array}$ & $\begin{array}{l}4.19 \\
\pm 0.53\end{array}$ & $27.9 \%$ & $28.8 \%$ & $23.5 \%$ \\
\hline $\begin{array}{l}\text { Numbness - } \\
\text { Max }\end{array}$ & $\begin{array}{l}7.29 \\
\pm 0.55\end{array}$ & $\begin{array}{l}5.43 \\
\pm 0.60\end{array}$ & $\begin{array}{l}5.00 \\
\pm 0.62\end{array}$ & $\begin{array}{l}5.00 \\
\pm 0.70\end{array}$ & $\begin{array}{l}5.52 \\
\pm 0.57\end{array}$ & $31.4 \%$ & $31.4 \%$ & $24.3 \%$ \\
\hline $\begin{array}{l}\text { Burning pain - } \\
\text { Usual }\end{array}$ & $\begin{array}{l}3.29 \\
\pm 0.66\end{array}$ & $\begin{array}{l}2.10 \\
\pm 0.58\end{array}$ & $\begin{array}{l}2.14 \\
\pm 0.52\end{array}$ & $\begin{array}{l}1.48 \\
\pm 0.49\end{array}$ & $\begin{array}{l}1.48 \\
\pm 0.43\end{array}$ & $35.0 \%$ & $55.0 \%$ & $55.0 \%$ \\
\hline $\begin{array}{l}\text { Burning Pain - } \\
\text { Max }\end{array}$ & $\begin{array}{l}5.71 \\
\pm 0.80\end{array}$ & $\begin{array}{l}3.33 \\
\pm 0.96\end{array}$ & $\begin{array}{l}3.43 \\
\pm 0.81\end{array}$ & $\begin{array}{l}2.43 \\
\pm 0.67\end{array}$ & $\begin{array}{l}3.00 \\
\pm 0.83\end{array}$ & $39.9 \%$ & $57.4 \%$ & $47.5 \%$ \\
\hline
\end{tabular}

${ }^{*} \pm$ refers to the standard error.

Table 3: Paired Samples T-tests by Type of Pain and Time Interval.

\begin{tabular}{|c|c|c|c|}
\hline Type of Pain & Time & Average Change & T-test P Value \\
\hline Tingling Pain - Usual & $7^{\text {th }}$ Treatment & -2.42857 & 0.000847 \\
\hline Tingling Pain - Usual & $10^{\text {th }}$ Treatment & -2.42857 & 0.001493 \\
\hline Tingling Pain - Usual & 1 Week Follow-up & -2.66667 & 0.000458 \\
\hline Tingling Pain - Usual & 1 Month Follow-up & -2.04762 & 0.0054 \\
\hline Tingling Pain - Max & $7^{\text {th }}$ Treatment & -2.61905 & 0.000614 \\
\hline Tingling Pain - Max & $10^{\text {th }}$ Treatment & -3.33333 & 0.00024 \\
\hline Tingling Pain - Max & 1 Week Follow-up & -3.66667 & 0.000113 \\
\hline Tingling Pain - Max & 1 Month Follow-up & -2.42857 & 0.001789 \\
\hline Numbness - Usual & $7^{\text {th }}$ Treatment & -1.09524 & $0.107867^{\star}$ \\
\hline Numbness - Usual & $10^{\text {th }}$ Treatment & -1.52381 & 0.013015 \\
\hline Numbness - Usual & 1 Week Follow-up & -1.57143 & 0.027392 \\
\hline Numbness - Usual & 1 Month Follow-up & -1.28571 & 0.047874 \\
\hline Numbness - Max & $7^{\text {th }}$ Treatment & -1.85714 & 0.002128 \\
\hline Numbness - Max & $10^{\text {th }}$ Treatment & -2.28571 & 0.000593 \\
\hline Numbness - Max & 1 Week Follow-up & -2.28571 & 0.001495 \\
\hline Numbness - Max & 1 Month Follow-up & -1.7619 & 0.007232 \\
\hline Burning Pain - Usual & $7^{\text {th }}$ Treatment & -1.19048 & $0.133425^{\star}$ \\
\hline
\end{tabular}




\begin{tabular}{|l|l|l|l|}
\hline Burning Pain - Usual & $10^{\text {th }}$ Treatment & -1.14286 & $0.162298^{*}$ \\
\hline Burning Pain - Usual & 1 Week Follow-up & -1.80952 & 0.013906 \\
\hline Burning Pain - Usual & 1 Month Follow-up & -1.80952 & 0.004612 \\
\hline & & & 0.018059 \\
\hline Burning Pain - Max & $7^{\text {th }}$ Treatment & -2.38095 & 0.011853 \\
\hline Burning Pain - Max & $10^{\text {th }}$ Treatment & -2.28571 & 0.001192 \\
\hline Burning Pain - Max & 1 Week Follow-up & -3.28571 & 0.002467 \\
\hline Burning Pain - Max & 1 Month Follow-up & -2.71429 & \\
\hline
\end{tabular}

*Not statistically significant.

Table 4: Toronto Neuropathy Score.

\begin{tabular}{|l|l|l|l|l|}
\hline Administration & Mean score & $\begin{array}{l}\text { Improvement from } \\
\text { Baseline }\end{array}$ & Standard Error & Standard Deviation \\
\hline Baseline before Treatment \#1 & 15.57 & & 0.874 & 4.007 \\
\hline Treatment \#7 & 12.38 & $20.5 \%$ & 1.348 & 6.176 \\
\hline One week after Treatment \#10 & 9.67 & $37.9 \%$ & 1.484 & 6.800 \\
\hline One month after Treatment \#10 & 11.43 & 26.65 & 1.410 & 6.462 \\
\hline
\end{tabular}

Table 5: Toronto Neuropathy Score - Paired Samples T-test.

\begin{tabular}{|l|l|l|}
\hline Time & Average Change & T-test P Value \\
\hline $7^{\text {th }}$ Treatment & -3.19048 & 0.025982 \\
\hline 1 Week Follow-up & -5.90476 & 0.000173 \\
\hline 1 Month Follow-up & -4.14286 & 0.001488 \\
\hline 6 Months Follow-up & -6.125 & 0.032037 \\
\hline
\end{tabular}

*Data available for 8 patients only.

Table 6: Semmes-Weinstein 5.07 Score.

\begin{tabular}{|l|l|l|l|l|}
\hline Administration & Mean Score & $\begin{array}{l}\text { Improvement from } \\
\text { Baseline }\end{array}$ & Standard Error & $\begin{array}{l}\text { Standard } \\
\text { Deviation }\end{array}$ \\
\hline Baseline before Treatment \#1 & 11.19 & & 0.930 & 4.262 \\
\hline Treatment \#7 & 15.57 & $39.1 \%$ & 0.917 & 4.202 \\
\hline One week after Treatment \#10 & 15.67 & $40.0 \%$ & 1.194 & 5.471 \\
\hline One month after Treatment \#10 & 15.76 & $40.8 \%$ & 1.132 & 5.186 \\
\hline
\end{tabular}

percent or more improvement in their pain levels across the different types of pain. Between 29 and 57 percent of subjects experienced 50 percent or more improvement in usual pain and between 33 and 52 percent experienced 50 percent or more improvement in maximum pain (Figure 2 ).

Measurements of level of neuropathy (Toronto Neuropathy Score - Table 4) showed that subjects had severe neuropathy at the start of treatment. Their neuropathy level decreased from severe to moderate, as measured one week after they completed the treatments and remained so one month after treatment completion (Table 5).

According to the Semmes Weinstein 5.07 (10 g) Monofilament Examination, subjects were able to feel between 39.1 and 40.8 percent more of the assessed spots on their feet. All had positive change and all changes were statistically significant. Implying an increase in the number of locations on the feet where
Table 7: Semmes-Weinstein $5.07(10 \mathrm{~g})$ Monofilament Examination -Paired Samples T-test.

\begin{tabular}{|l|l|l|}
\hline Time & Average Change & T-test $\mathbf{P}$ Value \\
\hline $7^{\text {th }}$ Treatment & 4.380952 & $5.37 \mathrm{E}-05$ \\
\hline 1 Week Follow-up & 4.47619 & 0.002103 \\
\hline 1 Month Follow-up & 4.571429 & $9.42 \mathrm{E}-05$ \\
\hline 6 Months Follow-up & 5.375 & 0.029018 \\
\hline
\end{tabular}

*Data available for 8 patients only.

subjects felt the monofilament (Table 6 and Table 7).

\section{Pain Questionnaire}

\section{Timing, change, and characteristics of pain}

At the onset of the treatments, $90.5 \%$ of the subjects experienced pain during the day and $76.2 \%$ experienced pain at night. Between 42.9 and $90.5 \%$ also experienced different kinds of pain, as shown in Figure 1 . The percentage of subjects experiencing pain during the day 
or night and the percentage of subjects experiencing different types of pain decreased with the treatments.

- After 10 treatments, $28.6 \%$ of subjects experienced a reduction of pain during the day. Between $28.6 \%$ and $33.4 \%$ of subjects experienced a reduction in the types of pain they were suffering from.

- One week following the last treatment, there was a further decrease in the percent of patients experiencing pain. $33.4 \%$ of subjects reported a decrease in their pain levels during the day. $23.8 \%$ of subjects reported a decrease in their pain levels during the night. Between $32.4 \%$ and $42.9 \%$ of subjects experienced a reduction in the different types of pain they were suffering from.

- One month following the last treatment, four of the six measures of pain were reported by the same percentage of subjects as at the end of the 10 treatments. The percent of subjects feeling pain at night decreased $19.1 \%$ and the percent of subjects having shooting pain decreased $18.1 \%$ from those experiencing pain at the start of treatments.

\section{Changes in usual and maximum pain}

Patients were also asked to rate their usual and worst tingling pain, numbness, and burning pain on a 10-point scale ranging from "0-No Pain" to "10-Worst Pain."

Table 2 shows mean scores calculated based on the ratings on the 10-point scale for usual and maximum tingling pain, numbness and burning pain after the initial treatment, Treatment \#7, Treatment \#10 (final treatment), one week and one month after Treatment \#10.The data shows improvement (decrease) in all types and levels of pain after the final treatment, and one week and one month after the final treatment.

- The level of improvement for usual pain after 10 treatments ranged from $27.9 \%$ (Numbness) to 53.2\% (Tingling Pain). For maximum pain, level of improvement ranged from $31.4 \%$ (Numbness) to 51.5\% (Tingling Pain).

- One week after the final treatment, level of improvement for usual pain ranged from 28.8\% (Numbness) to $58.5 \%$ (Tingling Pain). For maximum pain, level of improvement ranged from $31.4 \%$ (Numbness) to $56.6 \%$ (Tingling Pain).

- One month after the final treatment, level of improvement for usual pain ranged from 23.5\% (Numbness) to 55.0\% (Burning Pain). For maximum pain, level for improvement ranged from $24.3 \%$ (Numbness) to $47.5 \%$ (Burning Pain).

\section{Statistical Analysis}

\section{Paired samples T-test - pain questionnaire}

Paired Samples T-tests were conducted on the three types of pain at the usual and maximum levels comparing mean scores from baseline to Treatment \#7, \#10, one week and one month after the final treatment. As shown in Table 3, all showed negative average changes (reduction in pain) across the four time-benchmarks. All showed a statistically significant reduction in pain after the $7^{\text {th }}$ and $10^{\text {th }}$ treatments except in two cases. The reduction in pain was statistically significant for all usual and maximum types of pain at one week and one month of follow-up after completion of treatments.

\section{Improvement in pain levels}

A considerable percentage of subjects experienced a 50 percent or greater improvement in their usual and maximum pain. The data was recorded at three benchmarks: after completing the ten treatments, one week and one month after completing the treatments Figure $2(n=21)$.

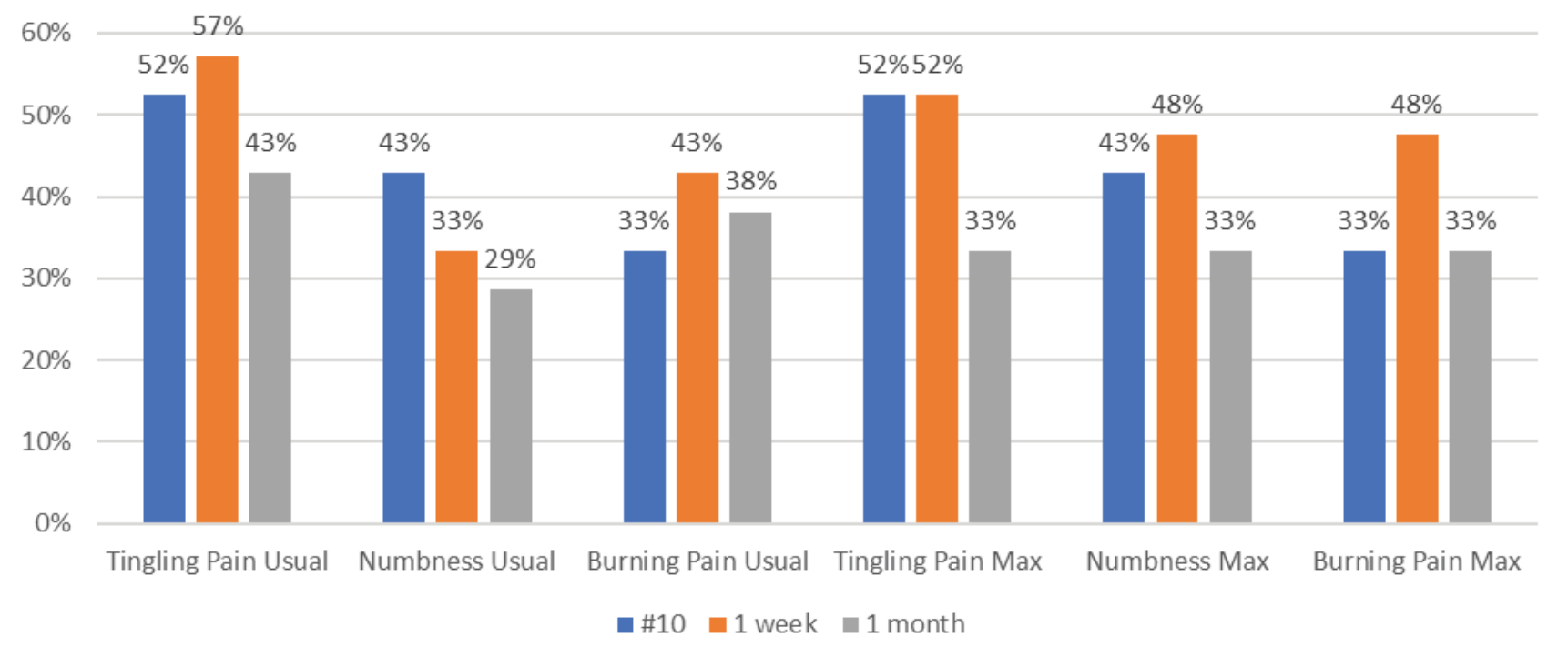

Figure 2: Percent of subjects showing 50\% improvement by type of pain $(n=21)$. 
- Between $43 \%$ and $57 \%$ experienced a $50 \%$ or greater improvement in their usual tingling pain and between $33 \%$ and $52 \%$ experienced improvement in their maximum tingling pain.

- Between $29 \%$ and $43 \%$ experienced $50 \%$ or more improvement in usual numbness and between $33 \%$ and $48 \%$ experienced improvement in their maximum numbness.

- Between $33 \%$ and $43 \%$ experienced $50 \%$ or more improvement in usual burning pain and between $33 \%$ and $48 \%$ experienced improvement in their maximum burning pain.

\section{Toronto neuropathy score}

The Toronto Neuropathy Score protocol was administered at baseline before Treatment \#1, after Treatment \#7, one-week and one-month after Treatment \#10. As shown in Table 4, patients had severe neuropathy at the start of treatment. Their neuropathy level decreased from severe to moderate, as measured one week after they completed the treatments and remained so one month after treatment completion.

The Paired Samples T-test shows reduction in level of neuropathy at all time points, including a six-month follow-up for eight patients. All changes are statistically significant (Table 5).

\section{Semmes-Weinstein 5.07 (10 g) monofilament examination}

Monofilament examination results are presented in Table 6.

The Paired Samples T-test compared baseline to seven treatments, baseline to one week after completion of the ten treatments and baseline to one month after treatment completion; all had positive change, and all were statistically significant (Table 7). The six months follow-up, performed on eight of the 21 patients, also showed a positive change and was statistically significant.

\section{Discussion}

This study showed that subjects reported positive results after utilizing NoxyPure that led to a statistically significant reduction in pain severity, and statistically significant improvements in sensitivity measurements. There were no side effects reported with the treatment.

Hypoxia, which results from an inadequate supply of oxygen is a major health concern. For example, over expression and stabilization of hypoxia-induced factor (HIF-1 $\alpha$ ) protein in tumor cells, due to hypoxia, results in poor prognosis and increased patient mortality. To increase oxygen tension in hypoxic tissues oxygen nanobubbles were utilized by researchers to reverse hypoxic conditions of cancer cells conceived in a custommade hypoxic chamber. The hypoxic conditions of the cells were evaluated through their expression of the HIF-1 $\alpha$ protein. The results indicated that the oxygen nanobubbles are successful at reversing hypoxia, down regulating HIF-1 $\alpha$, and improving cellular conditions. Important to note, that atypical vasculature reduces oxygen supply to the tumor tissue $[48,49]$.

Literature on the use of nanobubbles as a topical agent for tissue oxygenation is very sparse [50] although several important studies exist that demonstrates their utility. At the cellular level, the oxygen nanobubbles were shown to reduce HIF-1 $\alpha$ signaling, which may have important implications to topical tissue oxygenation. Perturbations in oxygen delivery to the tissue are identified as major factors to local tissue hypoxia which is related to health problems such as diabetes and peripheral vascular disease which when coupled with ischemia can lead to even further tissue damage [51].

Understanding the pathophysiology of pain and DPN may help to explain our preliminary study results. NoxyPure provides oxygen molecular gas locally at a relatively high partial pressure $\left(\mathrm{pO}_{2}\right)$, as well as a high concentration of oxygen UFNBs. Due to the relatively high gradient pressure and concentration, the molecular gas and its nanobubbles are theorized to diffuse deeply into the tissue rectifying the cells hypoxia condition.

With respect to the penetration of nanobubbles in tissue, there have been reports about adding fluids containing oxygen fine micro-bubbles to common infusion solutions in daily medical care. In one of the studies, it was demonstrated that these fine oxygen micro-bubbles may be sufficiently small to infuse safely into blood vessels for effectively improving blood oxygenation in cases of hypoxia, ischemic diseases, etc. It was shown that as the oxygen bubbles become smaller, such as in the size transition from micro-bubbles to nanobubbles, the partial pressure of oxygen $\left(\mathrm{pO}_{2}\right)$ increases dramatically [41]. While the partial pressure of oxygen in regular distilled water is approximately $200 \mathrm{mmHg}$ at concentrations of approximately $10^{2}$ $10^{3}$ microbubbles per milliliter, the partial pressure of oxygen increases to approximately $700 \mathrm{mmHg}$. When nanobubbles at a concentration of $10^{5}$ to $10^{6}$ are infused the partial pressure of oxygen increases to 1,100 $\mathrm{mmHg}$. Obviously, considering that our nanobubbles concentration is $10^{8}-10^{9}$ nanobubbles per milliliter, the partial pressure of oxygen will be greater than 1.5 atmospheric pressure, approaching similar conditions to HBOT topically and locally.

There is an unmet need for alternative treatment options for patients with DPN. Considering the bothersome and dangerous adverse effects that occur with existing treatment options for DPN patients, the identification, development, and incorporation of novel non-pharmacological treatment options that include nanotechnology formulated delivery systems will add important safe and effective options for patients and 
clinicians. Reductions in addiction, abuse, GI and other systemic side effects, toxicity issues, cardiovascular and renal implications may be able to be lessened through the use of these non-pharmacological approaches [52].

Enrolling and continued data collection from study participants was impacted due to the Corona Pandemic. 21 subjects completed the ten treatments, one-week follow-up and one-month follow-up.

Results from this IRB-approved observational study suggests that the non-pharmacological and nanotechnology formulated UltraFine Nanobubbles studied may provide a viable treatment alternative to pharmacological based therapies for DPN. Further analysis and formal clinical controlled trials are planned to confirm these results.

\section{Study Results Limitations}

This was an observational study based on a small sample of patients attending diverse clinical settings for the treatment of Diabetic Peripheral Neuropathy who consented to participate in this study. This interim analysis reported only on one group of patients who were treated with the NoxyPure. In future studies, control group and control-crossover group patients will be evaluated.

\section{Conclusion}

Peripheral neuropathy refers to a problem with the peripheral nerves. These nerves send messages from the central nervous system, the brain and the spinal cord, to the rest of the body. The most common cause of peripheral neuropathy is diabetes. Around 60 to $70 \%$ of people with diabetes have some degree of neuropathy. High blood-sugar levels cause damage to the walls of the tiny blood vessels that supply oxygen and nutrients to the nerve cells, particularly to the ends of hands and feet. As a result, not only does the skin become damaged, but the loss of sensation increases the risk of further damage and the onset of open wounds. In the US, diabetic neuropathy is the main cause of foot problems in people with diabetes. More than half of all people with diabetes are believed to have diabetic neuropathy [53].

The study results suggest that the nanotechnologyformulated UltraFine Nanobubbles Hydrogel emulsions are effective and safe for the relief of symptoms associated with Diabetic Peripheral Neuropathy. Significant reductions in pain were reported, which supports the use of novel nanotechnology systems, into the treatment algorithm for a multi-modal and pain management approach. These results support the use of this over-the-counter UltraFine Nanobubbles Hydrogel emulsions as a first-line non-pharmacological treatment option and should be considered by healthcare professionals and patients.

\section{Disclosure}

PeriphEX Corp. provided all equipment and test material (gel with UltraFine Nanobubbles) free of charge to the investigator study sites. Reasonable financial compensation was provided to the investigators for identification of study participants, collection and submission of study data. Jeffrey LaMour has received compensation from PeriphEX Corp. for his role as principal investigator and for providing protocolrequired services for the study. Peter L Hurwitz is Chairman of the Board for PeriphEX. Zvi Yaniv is Interim CEO of PeriphEX Corp. Ester Smith was compensated for statistical analysis. All authors, except Ester Smith, are advisors or shareholders of PeriphEX Corp.

\section{References}

1. Bril V, England JD, Franklin GM, Backonja M, Cohen J, et al. (2011) Evidence-based guideline: Treatment of painful diabetic neuropathy-report of the American Association of Neuromuscular and Electrodiagnostic Medicine, the American Academy of Neurology, and the American Academy of Physical Medicine \& Rehabilitation. Neurology 76: 1758-1765.

2. Javed S, Petropoulos IN, Alam U, Malik RA (2015) Treatment of painful diabetic neuropathy. Ther Adv Chronic Dis 6: 15-28.

3. Todorovic SM (2015) Is diabetic nerve pain caused by dysregulated ion channels in sensory neurons? Diabetes 64: 3987-3989.

4. Nukada $\mathrm{H}$ (2014) Ischemia and diabetic neuropathy. Handb Clin Neurol 126: 469-487.

5. Pop-Busui R, Boulton AJM, Feldman EL, Bril V, Freeman $R$, et al. (2017) Diabetic neuropathy: A position statement by the American Diabetes Association. Diabetes Care 40: 136-154.

6. Smith AG, Russell J, Feldman EL, Goldstein J, Peltier A, et al. (2006) Lifestyle intervention for pre-diabetic neuropathy. Diabetes Care 29: 1294-1299.

7. Oyibo SO, Prasad YD, Jackson NJ, Jude EB, Boulton AJ (2002) The relationship between blood glucose excursions and painful diabetic peripheral neuropathy: A pilot study. Diabet Med 19: 870-873.

8. Hamed E, Monem MA (2018) A review of diabetic peripheral neuropathy management given recent guidelines updates. Arch Gen Intern Med 2: 1-5.

9. Finnerup NB, Attal N, Haroutounian S, McNicol E, Baron $R$, et al. (2015) Pharmacotherapy for neuropathic pain in adults: A systematic review and meta-analysis. Lancet Neurol 14: 162-173.

10. Griebeler ML, Morey-Vargas OL, Brito JP, Tsapas A, Wang $Z$, et al. (2014) Pharmacologic interventions for painful diabetic neuropathy: An umbrella systematic review and comparative effectiveness network meta-analysis. Ann Intern Med 161: 639-649.

11. Quilici S, Chancellor J, Löthgren M, Simon D, Said G, et al. (2009) Meta-analysis of duloxetine vs. pregabalin and gabapentin in the treatment of diabetic peripheral neuropathic pain. BMC Neurol 9: 6.

12. Adriaensen $H$, Plaghki L, Mathieu $C$, Joffroy $A$, Vissers $K$ (2005) Critical review of oral drug treatments for diabetic neuropathic pain-clinical outcomes based on efficacy and 
safety data from placebo-controlled and direct comparative studies. Diabetes Metab Res Rev 21: 231-240.

13. Backonja M, Beydoun A, Edwards KR, Schwartz SL, Fonseca V, et al. (1998) Gabapentin for the symptomatic treatment of painful neuropathy in patients with diabetes mellitus: A randomized controlled trial. JAMA 280: 18311836.

14. Backonja M, Glanzman RL (2003) Gabapentin dosing for neuropathic pain: Evidence from randomized, placebocontrolled clinical trials. Clin Ther 25: 81-104.

15. Dallocchio C, Buffa C, Mazzarello P, Chiroli S (2000) Gabapentin vs. amitriptyline in painful diabetic neuropathy: An open-label pilot study. J Pain Symptom Manage 20: 280-285.

16. Dworkin $\mathrm{RH}$, O'Connor $\mathrm{AB}$, Backonja $\mathrm{M}$, Farrar JT, Finnerup NB, et al. (2007) Pharmacologic management of neuropathic pain: Evidence-based recommendations. Pain 132: 237-251.

17. Dissemond J, Kröger K, Storck M, Risse A, Engels P (2015) Topical oxygen wound therapies for chronic wounds: A review. J Wound Care 24: 53-63.

18. Vinogradov SV (2010) Nanogels in the race for drug delivery. Nanomedicine (Lond) 5: 165-168.

19. Stücker $M$, Struk $A$, Altmeyer $P$, Herde $M$, Baumgärtl $H$, et al. (2002) The cutaneous uptake of atmospheric oxygen contributes significantly to the oxygen supply of human dermis and epidermis. J Physiol 538: 985-994.

20. Plafki C, Peters P, Almeling M, Welslau W, Busch R (2000) Complications and side effects of hyperbaric oxygen therapy. Aviat Space Environ Med 71: 119-124.

21. Mutluoglu M, Cakkalkurt A, Uzun G, Aktas S (2014) Topical oxygen for chronic wounds: A PRO/CON Debate. J Am Coll Clin Wound Spec 5: 61-65.

22. Neamtu I, Rusu AG, Diaconu A, Nita LE, Chiriac AP (2017) Basic concepts and recent advances in nanogels as carriers for medical applications. Drug Deliv 24: 539-557.

23. Vinogradov SV (2007) Polymeric nanogel formulations of nucleoside analogs. Expert Opin Drug Deliv 4: 5-17.

24. Kabanov AV, Vinogradov SV (2009) Nanogels as pharmaceutical carriers: Finite networks of infinite capabilities. Angew Chem Int Ed Engl 48: 5418-5429.

25. Ferreira SA, Gama FM, Vilanova M (2013) Polymeric nanogels as vaccine delivery systems. Nanomedicine 9 : 159-173.

26. Singh N, Nisha, Gill V, Gill P (2013) Nanogel based artificial chaperone technology: An overview. Am J Adv Drug Deliv 1: 271-276.

27. Arnfast L, Madsen CG, Jorgensen L, Baldursdottir S (2014) Design and processing of nanogels as delivery systems for peptides and proteins. Ther Deliv 5: 691-708.

28. Nopphadol U, Pyo S-G, Park HH, Parkl H (2014) Fabrication of nanogels for delivery of molecules. J Nanosci Nanotechnol 14: 7363-7373.

29. Mavuso S, Marimuthu T, Choonara YE, Kumar $P$, du Toit LC, et al. (2015) A review of polymeric colloidal nanogels in transdermal drug delivery. Curr Pharm Des 21: 2801-2813.

30. Merino S, Martín C, Kostarelos K, Prato M, Vázquez E (2015) Nanocomposite hydrogels: 3D polymer-nanoparticle synergies for on-demand drug delivery. ACS Nano 9: 46864697.
31. Molina M, Asadian-Birjand M, Balach J, Bergueiro J, Miceli E, et al. (2015) Stimuli-responsive nanogel composites and their application in nanomedicine. Chem Soc Rev 44: 61616186.

32. Sivaram AJ, Rajitha $P$, Maya $S$, Jayakumar R, Sabitha $M$ (2015) Nanogels for delivery, imaging and therapy. Wiley Interdiscip Rev Nanomed Nanobiotechnol 7: 509-533.

33. Tahara Y, Akiyoshi K (2015) Current advances in selfassembled nanogel delivery systems for immunotherapy. Adv Drug Deliv Rev 95: 65-76.

34. Wang Y, Xu H, Ma L (2015) Recent advances of thermally responsive nanogels for cancer therapy. Ther Deliv 6: $1157-1169$

35. Khoee S, Asadi H (2016) Nanogels: chemical approaches to preparation. In: Encyclopedia of biomedical polymers and polymeric biomaterials. Taylor and Francis, New York, USA, 5266-5293.

36. Soni KS, Desale SS, Bronich TK (2016) Nanogels: an overview of properties, biomedical applications and obstacles to clinical translation. J Control Release 240: 109-126.

37. Zhang H, Zhai Y, Wang J, Zhai G (2016) New progress and prospects: The application of nanogel in drug delivery. Mater Sci Eng C Mater Biol Appl 60: 560-568.

38. Vogt A, Combadiere B, Hadam S, Stieler KM, Lademann J, et al. (2006) $40 \mathrm{~nm}$, but not 750 or $1,500 \mathrm{~nm}$, nanoparticles enter epidermal CD1a+ cells after transcutaneous application on human skin. J Invest Dermatol 126: 13161322.

39. Schneider M, Stracke F, Hansen S, Schaefer UF (2009) Nanoparticles and their interactions with the dermal barrier. Dermatoendocrinol 1: 197-206.

40. Khan MS, Hwang J, Lee K, Choi Y, Kim K, et al. (2018) Oxygen-carrying micro/nanobubbles: Composition, synthesis techniques and potential prospects in phototriggered theranostics. Molecules 23: 2210.

41. Matsuki N, Ishikawa $T$, Ichiba $S$, Shiba N, Ujike $Y$, et al. (2014) Oxygen supersaturated fluid using fine micro/ nanobubbles. Int J Nanomedicine 9: 4495-4505.

42. Fix SM, Papadopoulou V, Velds H, Kasoji SK, Rivera JN, et al. (2018) Oxygen microbubbles improve radiotherapy tumor control in a rat fibrosarcoma model - A preliminary study. PLoS One 13: e0195667.

43. Bohr Effect. Wikipedia. Last edited on 17 February 2021. https://en.wikipedia.org/wiki/Bohr_effect

44. Juffermans LJ, Dijkmans PA, Musters RJ, van Wamel A, Bouakaz A, et al. (2004) Local drug and gene delivery through microbubbles and ultrasound. Neth Heart $\mathrm{J} 12$ : 394-399.

45. Cavalli R, Bisazza A, Giustetto P, Civra A, Lembo D, et al. (2009) Preparation and characterization of dextran nanobubbles for oxygen delivery. International Journal of Pharmaceutics 381: 160-165.

46. US $10,624,841$ \& US 10,821,081.

47. Faul F, Erdfelder E, Lang AG, Buchner A (2007) G*Power 3: A flexible statistical power analysis program for the social, behavioral, and biomedical sciences. Behavior Research Methods 39: 175-191.

48. Khan MS, Hwang J, Seo Y, Shin K, Lee K, et al. (2018) Engineering oxygen nanobubbles for the effective reversal of hypoxia. Artif Cells Nanomed Biotechnol 46: S318-S327. 
49. Owen J, McEwan C, Nesbitt $H$, Bovornchutichai $P$, Averre R, et al. (2016) Reducing tumour hypoxia via oral administration of oxygen nanobubbles. PLoS One 11: e0168088.

50. Sayadi LR, Banyard DA, Ziegler ME, Obagi Z, Prussak J, et al. (2018) Topical oxygen therapy \& micro/nanobubbles: A new modality for tissue oxygen delivery. Int Wound J 15: 363-374.

51. Hinck D, Franke A, Gatzka F (2010) Use of vacuum-assisted closure negative pressure wound therapy in combat-related injuries--literature review. Mil Med 175: 173-181.

52. Wang X, Kang J, Liu Q, Tong T, Quan H (2020) Fighting diabetes mellitus: Pharmacological and nonpharmacological approaches. Curr Pharm Des 26: 49925001.

53. Webberley, Helen, What is Peripheral Neuropathy? November 27 2017. https://www.medicalnewstoday.com/ articles/147963. 